\title{
Andreprevotia lacus sp. nov., isolated from a fish-culture pond
}

\author{
Shih-Yi Sheu, ${ }^{1}$ Tzu Fang Chiu, ${ }^{1}$ Jui-Hsing Chou, ${ }^{2}$ Der-Shyan Sheu, ${ }^{1}$ \\ A. B. Arun, ${ }^{2}$ Chiu-Chung Young, ${ }^{2}$ Chaolun Allen Chen, ${ }^{3}$ \\ Jih-Terng Wang ${ }^{4}$ and Wen-Ming Chen ${ }^{5}$ \\ ${ }^{1}$ Department of Marine Biotechnology, National Kaohsiung Marine University, Kaohsiung, \\ Taiwan, ROC \\ ${ }^{2}$ Department of Soil Environmental Sciences, College of Agriculture and Natural Resources, \\ National Chung Hsing University, Taichung, Taiwan, ROC \\ ${ }^{3}$ Research Center for Biodiversity, Academia Sinica, Nangang 115, Taipei, Taiwan, ROC \\ ${ }^{4}$ Institute of Biotechnology, Tajen University, Yanpu, Pingtung 907, Taiwan, ROC \\ ${ }^{5}$ Laboratory of Microbiology, Department of Seafood Science, National Kaohsiung Marine \\ University, No. 142, Hai-Chuan Rd. Nan-Tzu, Kaohsiung City 811, Taiwan, ROC
}

Correspondence

Wen-Ming Chen p62365@ms28.hinet.net
The genus Andreprevotia, a member of the family Neisseriaceae, currently encompasses only one species, namely Andreprevotia chitinilytica (type strain $\mathrm{JS} 11-7^{\mathrm{T}}$ ), isolated from Halla Mountain forest soil, Jeju Island, Korea (Weon et al., 2007). During our investigations of the biodiversity of bacteria associated with a fish-culture pond located in Taoyuan County, Taiwan, several ivory-coloured bacterial colonies were isolated on R2A agar (BD Difco). Strains showing similar colony morphology were selected and a representative strain, GFC- $1^{\mathrm{T}}$, was selected for detailed analyses. Strain $\mathrm{GFC}-1^{\mathrm{T}}$ was maintained on R2A agar at $25{ }^{\circ} \mathrm{C}$. Subcultivation was performed on R2A agar at $25{ }^{\circ} \mathrm{C}$ for between 48 and $72 \mathrm{~h}$. On this medium, strain GFC- $1^{\mathrm{T}}$ was able to grow at $15-37{ }^{\circ} \mathrm{C}$, but not at 10 or $40{ }^{\circ} \mathrm{C}$. The strain was preserved at $-80{ }^{\circ} \mathrm{C}$ in nutrient broth (NB; Difco) with $20 \%(\mathrm{v} / \mathrm{v})$ glycerol or by lyophilization.

Cell morphology was observed by phase-contrast microscopy (DM 2000; Leica) at lag, exponential and stationary

The GenBank/EMBL/DDBJ accession number for the 16S rRNA gene sequence of Andreprevotia lacus GFC-1 ${ }^{\top}$ is EU287926. phases of growth. Motility was tested by the hanging-drop method. Spot Test Flagella Stain (BD Difco) was used for flagellum staining. A Gram Stain Set S kit (BD Difco) and the Ryu non-staining $\mathrm{KOH}$ method (Powers, 1995) were adopted for testing the Gram-staining reaction. Poly- $\beta$ hydroxybutyrate granule accumulation was observed under light microscopy after staining the cells with Sudan black. Details of cell morphology are provided in the species description. The $\mathrm{pH}$ range for growth was determined by measuring the $\mathrm{OD}_{600}$ of the culture grown in NB that had been adjusted prior to sterilization to various $\mathrm{pH}$ values ( $\mathrm{pH} 4.0-10.0$ at intervals of $0.5 \mathrm{pH}$ units), using appropriate biological buffers (Chung et al., 1995). Verification of the $\mathrm{pH}$ values after autoclaving revealed only minor changes. Tolerance to $\mathrm{NaCl}$ was tested in $\mathrm{NB}$ prepared according to the formula of the BD Difco medium, but adjusted to different $\mathrm{NaCl}$ concentrations [0, 0.5 and 1.0$3.0 \%(\mathrm{w} / \mathrm{v})$ at intervals of $1.0 \%]$. Anaerobic growth was checked by using the Oxoid AnaeroGen system. Strain GFC $-1^{\mathrm{T}}$ was examined for catalase, oxidase, DNase, urease and lipase activities and hydrolysis of starch, casein, chitin, 
CM-cellulose, aesculin, tyrosine and Tweens 20, 40, 60 and 80 by using standard approaches (Gerhardt et al., 1994). Phenotypic characteristics [biochemical tests and carbonsource utilization; API 50CH, API ZYM and API 20NE (all from bioMérieux)] were investigated.

The $16 \mathrm{~S}$ rRNA gene sequence was analysed as described by Chen et al. (2001). Analysis of the sequence data was performed by using the software packages BioEdit (Hall, 1999) and MEGA version 3.1 (Kumar et al., 2004) after multiple alignments of the data by CLUSTAL_X (Thompson et al., 1997). A distance-matrix method (distance options according to the Kimura two-parameter model; Kimura, 1983) including clustering by the neighbour-joining (Saitou \& Nei, 1987) (Fig. 1), maximum-parsimony (Kluge \& Farris, 1969) and maximum-likelihood (Felsenstein, 1981) methods was used. In each case, bootstrap values were calculated based on 1000 replications. The 16S rRNA gene sequence of strain GFC- $1^{\mathrm{T}}$ was a partial stretch of $1398 \mathrm{bp}$ (GenBank accession no. EU287926). 16S rRNA gene sequence analysis indicated that strain GFC- $1^{\mathrm{T}}$ belongs to the family Neisseriaceae of the class Betaproteobacteria. Strain $\mathrm{GFC}-1^{\mathrm{T}}$ formed a distinct subline within the genus Andreprevotia. Sequence-similarity calculations (over $1350 \mathrm{bp}$ ) indicated that strain GFC- $1^{\mathrm{T}}$ was related closely to A. chitinilytica JS1 $1-7^{\mathrm{T}}(97.0 \%$ 16S rRNA gene sequence similarity), Deefgea rivuli WB $3.4-79^{\mathrm{T}}(95.6 \%)$ and Silvimonas terrae $\mathrm{KM}-45^{\mathrm{T}}(94.9 \%)$. Lower sequence similarities $(<94.5 \%)$ were found with representative members of all other genera listed in Fig. 1. The overall topologies of the phylogenetic trees obtained with neighbour-joining, maximum-likelihood or maximum-parsimony methods were similar.

Fatty acid methyl esters were prepared, separated and identified according to the instructions of the Microbial Identification system (Microbial ID; Sasser, 1990). The predominant fatty acid constituents of strain $\mathrm{GFC}-1^{\mathrm{T}}$ were summed feature $3\left(\mathrm{C}_{16: 1} \omega 7 c\right.$ and/or iso- $\left.\mathrm{C}_{15: 0} 2-\mathrm{OH}\right), \mathrm{C}_{16: 0}$ and $\mathrm{C}_{18: 1} \omega 7 c$. The fatty acid profile of strain GFC-1 ${ }^{\mathrm{T}}$ was consistent with that reported for A. chitinilytica JS11-7 ${ }^{\mathrm{T}}$, but their fatty acid proportions differed (Table 1). The DNA $\mathrm{G}+\mathrm{C}$ content of strain GFC- $1^{\mathrm{T}}$ was estimated as described by Mesbah et al. (1989) to be $63.0 \pm 0.1 \mathrm{~mol} \%(n=3)$. DNADNA hybridization experiments were carried out with $A$. chitinilytica JS11-7 ${ }^{\mathrm{T}}$ by the method outlined by Ezaki et al. (1989). The results of DNA-DNA hybridization indicated low levels $(27.5 \pm 6.8 \%)$ of relatedness between strain GFC$1^{\mathrm{T}}$ and A. chitinilytica JS11-7 ${ }^{\mathrm{T}}$ (Wayne et al., 1987).

Sensitivity of strain GFC- $1^{\mathrm{T}}$ to antibiotics was tested by spreading cells ( 0.5 on the McFarland scale) on MuellerHinton agar (BD Difco) plates. The antibiotic discs (Oxoid) contained the following antibiotics: ampicillin $(10 \mu \mathrm{g})$, chloramphenicol $(30 \mu \mathrm{g})$, gentamicin $(10 \mu \mathrm{g})$, kanamycin $(30 \mu \mathrm{g})$, nalidixic acid $(30 \mu \mathrm{g})$, novobiocin $(30 \mu \mathrm{g})$, rifampicin $(5 \mu \mathrm{g})$, penicillin $\mathrm{G}(10 \mu \mathrm{g})$, streptomycin $(10 \mu \mathrm{g})$, sulfamethoxazole plus trimethoprim $(23.75+1.25 \mu \mathrm{g})$ or tetracycline $(30 \mu \mathrm{g})$. The effect of antibiotics on cell growth was assessed after 3 days incubation. Detailed results of the phenotypic and biochemical characterization of strain GFC- $1^{\mathrm{T}}$ are provided in Table 2 and in the species description. Carbon substrateutilization tests with various sugars and organic acids as substrates showed few positive results.

Strain GFC- $1^{\mathrm{T}}$ is clearly different from A. chitinilytica and occupies a separate position in the genus Andreprevotia. This genotypic insight was supported by a unique combination of chemotaxonomic and biochemical characteristics (Tables 1 and 2). It is clear from the genotypic and phenotypic data that strain $\mathrm{GFC}-1^{\mathrm{T}}$ represents a second species of the genus Andreprevotia. The name Andreprevotia lacus sp. nov. is proposed for this taxon.

\section{Description of Andreprevotia lacus sp. nov.}

Andreprevotia lacus (la'cus. L. gen. n. lacus of a lake, basin or tank, referring to the place of isolation of the type strain).

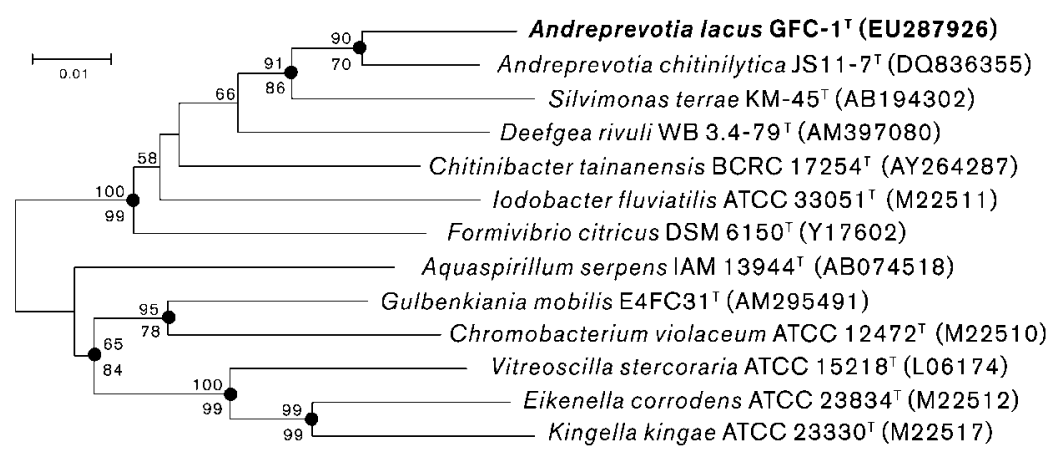

Fig. 1. Phylogenetic tree based on $16 \mathrm{~S}$ rRNA gene sequences, showing the phylogenetic position of strain GFC- $1^{\top}$ (Andreprevotia lacus sp. nov.) and related taxa in the class Betaproteobacteria. The neighbour-joining method was employed with the distance model of Jukes \& Cantor (1969). Numbers at nodes are percentage bootstrap values $(>50 \%)$ based on both the neighbour-joining (above nodes) and maximum-parsimony (below nodes) tree-making algorithms. Filled circles indicate branches of the tree that were also recovered by using the maximum-likelihood and maximum-parsimony tree-making algorithms. Bar, 0.01 substitutions per nucleotide position. 
Table 1. Fatty acid compositions of strain GFC-1 ${ }^{\top}$ (Andreprevotia lacus sp. nov.) and A. chitinilytica JS11-7

Strains: 1, GFC- $1^{\mathrm{T}} ; 2$, A. chitinilytica $\mathrm{JS} 11-7^{\mathrm{T}}$. Strain $\mathrm{GFC}-1^{\mathrm{T}}$ was cultured on tryptic soy agar (BD Difco) at $28{ }^{\circ} \mathrm{C}$ for $48 \mathrm{~h}$ as described for A. chitinilytica JS11- $7^{\mathrm{T}}$ (Weon et al., 2007). Values are percentages of total fatty acid content.,$-<0.5 \%$ or not detected. For unsaturated fatty acids, the position of the double bond is located by counting from the methyl $(\omega)$ end of the carbon chain.

\begin{tabular}{|lcc|}
\hline Fatty acid & $\mathbf{1}$ & $\mathbf{2}$ \\
\hline $\mathrm{C}_{10: 0} 3-\mathrm{OH}$ & 1.8 & 1.6 \\
$\mathrm{C}_{12: 0}$ & - & 2.7 \\
$\mathrm{C}_{12: 0} 3-\mathrm{OH}$ & 2.1 & 2.0 \\
$\mathrm{C}_{14: 0}$ & 5.7 & 0.6 \\
$\mathrm{C}_{15: 1} \omega 6 c$ & 0.7 & 1.0 \\
$\mathrm{C}_{16: 0}$ & 25.9 & 31.1 \\
$\mathrm{C}_{17: 0}$ & 0.7 & 1.0 \\
$\mathrm{C}_{17: 0}$ cyclo & - & 2.3 \\
$\mathrm{C}_{17: 1} \omega 6 c$ & 0.6 & - \\
$\mathrm{C}_{18: 0}$ & - & 0.7 \\
$\mathrm{C}_{18: 1} \omega 7 c$ & 22.2 & 15.8 \\
Summed feature $3^{*}$ & 38.5 & 39.5 \\
\hline
\end{tabular}

${ }^{\star}$ Summed features are groups of fatty acids that cannot be separated by GLC with the MIDI system. Summed feature 3 contains $\mathrm{C}_{16: 1} \omega 7 c$ and/or iso- $\mathrm{C}_{15: 0} 2-\mathrm{OH}$.

Cells are Gram-negative, aerobic, rod-shaped, non-sporeforming and motile by means of a single polar flagellum. Poly- $\beta$-hydroxybutyrate granules are accumulated. After $48 \mathrm{~h}$ growth on R2A agar at $25{ }^{\circ} \mathrm{C}$, the mean cell size is $0.5 \mu \mathrm{m}$ in width and $1.0-2.0 \mu \mathrm{m}$ in length. Visible, round, entire, convex and ivory-coloured colonies are formed on R2A agar. Colony size is approximately $1.8-2.2 \mathrm{~mm}$ in diameter after $48 \mathrm{~h}$ at $25^{\circ} \mathrm{C}$. Growth occurs at $15-37^{\circ} \mathrm{C}$, $0-1 \%(\mathrm{w} / \mathrm{v}) \mathrm{NaCl}$ and $\mathrm{pH} 7.0-9.0$ [optimum at $30^{\circ} \mathrm{C}, 0-$ $0.5 \%(\mathrm{w} / \mathrm{v}) \mathrm{NaCl}$ and $\mathrm{pH} 7.0]$. Positive for oxidase and catalase activities and chitin hydrolysis. Negative for hydrolysis of DNase, lipase (corn oil), Tweens 20, 40, 60 and 80, starch, CM-cellulose, aesculin, tyrosine and casein. Positive (API 20NE) for nitrate reduction, glucose acidification, arginine dihydrolase, urease, $\beta$-glucosidase, protease, $\beta$-galactosidase and assimilation of glucose, arabinose, mannose, mannitol, $\mathrm{N}$-acetylglucosamine, maltose, adipate, malate and citrate; negative for indole production and assimilation of phenylacetate, gluconate and caprate. Positive (API ZYM) for alkaline phosphatase, C4 esterase, C8 esterase lipase, leucine arylamidase, acid phosphatase, naphthol-AS-BI-phosphohydrolase, $\alpha$-glucosidase and $N$-acetyl- $\beta$-glucosaminidase; negative for C14 lipase, valine arylamidase, cystine arylamidase, trypsin, $\alpha$ chymotrypsin, $\alpha$-galactosidase, $\beta$-galactosidase, $\beta$-glucuronidase, $\beta$-glucosidase, $\alpha$-mannosidase and $\alpha$-fucosidase. Major fatty acids are summed feature $3\left(\mathrm{C}_{16: 1} \omega 7 \mathrm{c}\right.$ and/or iso- $\left.\mathrm{C}_{15: 0} 2-\mathrm{OH}\right), \mathrm{C}_{16: 0}$ and $\mathrm{C}_{18: 1} \omega 7 c$. Additional phenotypic properties are listed in Table 2. The following
Table 2. Characteristics that distinguish strain GFC-1 ${ }^{\top}$ (Andreprevotia lacus sp. nov.) from A. chitinilytica JS11-7

Strains: $1, \mathrm{GFC}-1^{\mathrm{T}} ; 2$, A. chitinilytica $\mathrm{JS} 11-7^{\mathrm{T}}$. Data for isolation source and DNA G $+\mathrm{C}$ content for A. chitinilytica JS1 $1-7^{\mathrm{T}}$ were taken from Weon et al. (2007); all other data listed were obtained in this study. Both strains were positive for utilization of D-ribose, Dgalactose, D-fructose, $\mathrm{N}$-acetylglucosamine, D-lyxose and potassium 5-ketogluconate. The following characteristics were negative for both strains: utilization of glycerol, erythritol, L-xylose, adonitol, methyl $\beta$ D-xylopyranoside, L-sorbose, dulcitol, inositol, D-sorbitol, methyl $\alpha$ D-mannopyranoside, methyl $\alpha$-D-glucopyranoside, amygdalin, arbutin, salicin, D-lactose, $\alpha$-melibiose, sucrose, trehalose, inulin, $\alpha$ melezitose, $\alpha$-raffinose, xylitol, turanose, D-tagatose, L-fucose, Larabitol and potassium 2-ketogluconate. + , Positive; - , negative; $\mathrm{R}$, resistant; s, sensitive.

\begin{tabular}{|c|c|c|}
\hline Characteristic & 1 & 2 \\
\hline Isolation source & Fish-culture pond & Forest soil \\
\hline Arginine dihydrolase & + & - \\
\hline Urease & + & - \\
\hline$\beta$-Galactosidase & + & - \\
\hline$\beta$-Glucosidase & - & + \\
\hline Alkaline phosphatase & + & - \\
\hline C8 esterase lipase & + & - \\
\hline \multicolumn{3}{|l|}{ Assimilation of (API 20NE): } \\
\hline Glucose & + & - \\
\hline Arabinose & + & - \\
\hline Mannose & + & - \\
\hline Maltose & + & - \\
\hline Gluconate & - & + \\
\hline Adipate & + & - \\
\hline Malate & + & - \\
\hline Citrate & + & - \\
\hline \multicolumn{3}{|l|}{ Hydrolysis of: } \\
\hline Starch & - & + \\
\hline Corn oil & - & + \\
\hline Tween 20 & - & + \\
\hline Tween 40 & - & + \\
\hline Tween 60 & - & + \\
\hline Tween 80 & - & + \\
\hline Susceptibility to nalidixic acid & S & $\mathrm{R}$ \\
\hline DNA G + C content $(\mathrm{mol} \%)$ & 63 & 62 \\
\hline
\end{tabular}

compounds are utilized in the API $50 \mathrm{CH}$ test system: Dribose, D-galactose, D-glucose, D-fructose, D-mannose, $\mathrm{N}$ acetylglucosamine, D-lyxose and potassium 5-ketogluconate. Negative for assimilation of glycerol, erythritol, Darabinose, L-arabinose, D-xylose, L-xylose, adonitol, methyl $\beta$-D-xylopyranoside, L-sorbose, L-rhamnose, dulcitol, inositol, D-mannitol, D-sorbitol, methyl $\alpha$-D-mannopyranoside, methyl $\alpha$-D-glucoside, amygdalin, arbutin, aesculin ferric citrate, salicin, cellobiose, maltose, D-lactose, $\alpha$ melibiose, sucrose, trehalose, inulin, $\alpha$-melezitose, $\alpha$ raffinose, starch, glycogen, xylitol, $\beta$-gentiobiose, turanose, D-tagatose, D-fucose, L-fucose, D-arabitol, L-arabitol, potassium gluconate and potassium 2-ketogluconate. Sensitive to tetracycline, kanamycin, rifampicin, gentamicin, 
chloramphenicol, nalidixic acid, novobiocin and streptomycin, but resistant to ampicillin, penicillin $G$ and sulfamethoxazole plus trimethoprim. The DNA G+C content of the type strain is $63.0 \mathrm{~mol} \%$.

The type strain is $\mathrm{GFC}-1^{\mathrm{T}} \quad\left(=\mathrm{BCRC} \quad 17832^{\mathrm{T}}=\mathrm{LMG}\right.$ $\left.24502^{\mathrm{T}}\right)$, isolated from a fish-culture pond located in Taoyuan County, Taiwan.

\section{Acknowledgements}

We thank Dr Soon-Wo Kwon (KACC, National Institute of Agricultural Biotechnology, Republic of Korea), who kindly provided A. chitinilytica JS1 $1-7^{\mathrm{T}}$. This study was funded by grants from the National Science Council (96-2313-B-022-001-MY3) and Academia Sinica (Thematic Grant 2008-2010), Taipei, Taiwan, ROC.

\section{References}

Chen, W. M., Laevens, S., Lee, T. M., Coenye, T., de Vos, P., Mergeay, M. \& Vandamme, P. (2001). Ralstonia taiwanensis sp. nov., isolated from root nodules of Mimosa species and sputum of a cystic fibrosis patient. Int J Syst Evol Microbiol 51, 1729-1735.

Chung, Y. C., Kobayashi, T., Kanai, H., Akiba, T. \& Kudo, T. (1995). Purification and properties of extracellular amylase from the hyperthermophilic archeon Thermococcus profundus DT5432. Appl Environ Microbiol 61, 1502-1506.

Ezaki, T., Hashimoto, Y. \& Yabuuchi, E. (1989). Fluorometric deoxyribonucleic acid-deoxyribonucleic acid hybridization in microdilution wells as an alternative to membrane filter hybridization in which radioisotopes are used to determine genetic relatedness among bacterial strains. Int J Syst Bacteriol 39, 224-229.

Felsenstein, J. (1981). Evolutionary trees from DNA sequences: a maximum likelihood approach. J Mol Evol 17, 368-376.

Gerhardt, P., Murray, R. G. E., Wood, W. A. \& Krieg, N. R. (editors) (1994). Methods for General and Molecular Bacteriology. Washington, DC: American Society for Microbiology.
Hall, T. A. (1999). BioEdit: a user-friendly biological sequence alignment editor and analysis program for Windows 95/98/NT. Nucleic Acids Symp Ser 41, 95-98.

Jukes, T. H. \& Cantor, C. R. (1969). Evolution of protein molecules. In Mammalian Protein Metabolism, vol. 3, pp. 21-132. Edited by H. N. Munro. New York: Academic Press.

Kimura, M. (1983). The Neutral Theory of Molecular Evolution. Cambridge: Cambridge University Press.

Kluge, A. G. \& Farris, F. S. (1969). Quantitative phyletics and the evolution of anurans. Syst Zool 18, 1-32.

Kumar, S., Tamura, K. \& Nei, M. (2004). MEGA3: integrated software for molecular evolutionary genetics analysis and sequence alignment. Brief Bioinform 5, 150-163.

Mesbah, M., Premachandran, U. \& Whitman, W. B. (1989). Precise measurement of the $\mathrm{G}+\mathrm{C}$ content of deoxyribonucleic acid by high-performance liquid chromatography. Int J Syst Bacteriol 39, 159-167.

Powers, E. M. (1995). Efficacy of the Ryu nonstaining $\mathrm{KOH}$ technique for rapidly determining gram reactions of food-borne and waterborne bacteria and yeasts. Appl Environ Microbiol 61, 3756-3758.

Saitou, N. \& Nei, M. (1987). The neighbor-joining method: a new method for constructing phylogenetic trees. Mol Biol Evol 4, 406-425.

Sasser, M. (1990). Identification of bacteria by gas chromatography of cellular fatty acids, MIDI Technical Note 101. Newark, DE: MIDI Inc.

Thompson, J. D., Gibson, T. J., Plewniak, F., Jeanmougin, F. \& Higgins, D. G. (1997). The CLUSTAL_X windows interface: flexible strategies for multiple sequence alignment aided by quality analysis tools. Nucleic Acids Res 25, 4876-4882.

Wayne, L. G., Brenner, D. J., Colwell, R. R., Grimont, P. A. D., Kandler, O., Krichevsky, M. I., Moore, L. H., Moore, W. E. C., Murray, R. G. E. \& other authors (1987). International Committee on Systematic Bacteriology. Report of the ad hoc committee on reconciliation of approaches to bacterial systematics. Int J Syst Bacteriol 37, 463-464.

Weon, H. Y., Kim, B. Y., Yoo, S. H., Joa, J. H., Kwon, S. W. \& Kim, W. G. (2007). Andreprevotia chitinilytica gen. nov., sp. nov., isolated from forest soil from Halla mountain, Jeju Island, Korea. Int J Syst Evol Microbiol 57, 1572-1575. 